\title{
Histories
}

\section{History of post-traumatic syringomyelia: post traumatic syringomyelia prior to 1920}

\author{
JR Silver*,1 \\ ${ }^{1} 8$ High Street, Wendover, Bucks HP22 6EA, UK
}

\begin{abstract}
Study design: Review of five cases of post-traumatic syringomyelia originally described between $1898-1920$.

Objectives: To describe the earliest presentation of post-traumatic syringomyelia and to compare to modern day views of this condition.

Setting: Historical review.

Results: Pathogenesis and interpretation of the findings are discussed in the light of current knowledge.

Conclusion: Credit for the first description of post-traumatic syringomyelia (in 1898) should go to $\mathrm{W}$ Wagner and P Stolper.

Spinal Cord (2001) 39, 176-183
\end{abstract}

Keywords: post traumatic syringomyelia prior to 1920; four new cases; one old case

\section{Introduction}

The clinical syndrome of post traumatic syringomyelia complicating major spinal trauma which develops many months after spinal injury was first elucidated by Barnett and Jousse ${ }^{1}$ in a series of papers and monographs between 1963 and 1970. The cyst was found both at post mortem and operation to commence at the site of spinal injury. It could progress both caudally and rostrally and give rise to progressive loss of function in the upper limbs so that a paraplegic patient could become a tetraplegic. The cyst originated from the site of trauma and it was postulated that it might come from the necrotic areas of tissue or haematomyelia at the site of trauma. Its relationship with compression and arachnoiditis was recognised. It was found to occur in only $1 \%$ of patients.

In recent years, with the availability of CT and MRI scanning, the incidence of post-traumatic syringomyelia, natural history, clinical features, particularly the extension of the lesion downwards, and operative treatment have been delineated further. Little progress has been made in determining the cause of this condition, its relationship to the small cyst found inevitably at the level of the original trauma to the spinal cord and myelomalacia. Why some patients develop syringomyelia and whether it can be

*Correspondence: JR Silver, 8 High Street, Wendover, Bucks HP22 6EA, UK influenced by the initial management is still unanswered.

The cyst has been observed to suddenly enlarge following coughing or straining with a dramatic deterioration in the patient's condition or the cyst can gradually enlarge over a period of years. This has led to a proliferation of papers and experimental work. The current view is that there is a mechanical filling of the cyst which is in communication with CSF and it has been speculated that the change in pressure causes the cyst to increase in size.

Barnett and Jousse $^{1}$ reviewed the literature and described five cases prior to 1920 (Strümpell $1880,{ }^{2}$ Bawli 1896, ${ }^{3}$ Weisenburg 1907 - 2 cases, ${ }^{4}$ Strong $1919^{5}$ ), 32 cases post 1940,17 in their own series and 19 personally communicated to them.

Whilst surveying the literature on the history of traumatic paraplegia prior to 1920 I found four further cases of post traumatic syringomyelia. The case of Bawli, which I am also including, was recorded by Wagner and Stolper ${ }^{6}$ with pertinent commentary. In view of the widespread interest in this condition today, I think it is worth recording the work of these early investigators and their views on the pathogenesis of this still unsolved mystery.

Case 1-JK Mitchell $1895^{7}$

In 1864 Drs Weir Mitchell, Morehouse and Keen published a book on the effects of gunshot wounds on 
nerves. This was on soldiers injured in the American War of Independence. This work was amplified in 1872 by Dr Weir Mitchell and a follow-up study on the clinical condition of the soldiers written by his son, JK Mitchell was published in 1895, 31 years after the initial study. Amongst the injuries of the spinal cord and its neighbourhood, the following case was presented.

Mr C, aged 19, was wounded at Gettysburg by a Minie-ball passing through the upper lip and jaw, and burying itself in the pharynx. He was unconscious for half an hour and then found himself paralysed in all four limbs. Within an hour power and sensation returned to his legs. Within $48 \mathrm{~h}$ power and sensation returned to his left arm.

Five weeks after his injury he had weakness of his right arm with limited ability to pronate and supinate the arm and some impairment of sensation. He had some loss of sensation behind the right ear. There was a mass of soft granulation at the back of his throat at the level of the third cervical vertebra from which pus oozed freely. The bullet was removed with splinters of bone. There was rapid improvement in his condition. Two fragments of a vertebra were subsequently discharged from the wound.

He was reviewed 27 years later at the age of $47 . \mathrm{He}$ could distinguish touch in the lower part of his body but not between hot and cold. All his movements were normal. He was complaining of pain in the back and shoulders, numbness below the waist, particularly from the calves downwards. He had some difficulty in controlling micturition.

Two years later, at the age of 49 , there had been a rapid change in his condition. He had marked symptoms of progressive paralysis. His gait was unsteady.

Mitchell remarked: 'Originally his return to health was complete enough to permit his re-enlistment, and in spite of the patient's complaints of his subjective sensations, his appearance and the evidence of an examination made even so late as two years ago, would have led to an inference of good health, and perhaps even to a suspicion of malingering.'

'Could the full extent of the injury have been known at first the prognosis must then have been most unfavorable. But it was not until recovery was nearly complete that the discharge from the wound of portions of a vertebra showed that the spinal canal had been actually opened by the crushing of the body of the third vertebra. If the patient's statement that he has difficulty in the differentiation of heat and cold be correct, there must have been some late alteration in the lateral columns'.

\section{Comment}

This patient showed the features of a traumatic spinal cord injury in the 3 rd cervical region confirmed by the discharge of pieces of the vertebra. He made a virtually complete recovery, to such a degree, that he was able to return to the army but 29 years after his injury, he showed the features of post traumatic syringomyelia: sudden deterioration in function, pain between the shoulder blades, long tract signs accompanied by bladder involvement, loss of power and spinothalamic involvement.

\section{Case 2-Hermann Schlesinger $1895^{8}$}

This case is described in Schlesinger's monograph on syringomyelia.

Mr U, a 53 year old male labourer, fell from the fourth floor. He was admitted to hospital unconscious. He was found to have fractures of the skull, upper and lower jaw and ribs. He was tender at the 12th thoracic vertebra where there was a large gibbus. There was loss of sensation up to one third of the thigh, absent knee and ankle jerks and priapism. Over the subsequent days the anaesthesia involving all modalities rapidly ascended to reach the groin.

On day 3 after injury he complained of pain in his back and abdomen. On day 10 he was incontinent of faeces. On day 11 he developed pressure sores over the sacrum. On day 45 he was placed on a water bed. His neurological condition remained the same but he developed oedema of the lower limbs and his pressure sores increased in size and depth. He died 76 days after injury.

A post mortem revealed cystitis and pyelonephritis. A $1 \mathrm{~cm}$ posterior shift of the 12 th thoracic vertebra was found causing pronounced compression of the cord. There was some callus formation on the anterior and posterior aspects of the 11th and 12th thoracic vertebrae. At the level of the lesion there was obliteration of the central canal and three cysts had formed. At the thoraco-lumbar junction the cord was completely crushed. The cysts from the level of the lesion extended upwards to the upper thoracic cord and there was distension of the central canal.

\section{Comment}

Schlesinger considered this to be a case of syringomyelia and included it in his monograph.

The patient showed the features of post traumatic syringomyelia pain in his back and ascent of the lesion. This was confirmed by there being several cysts extending from the level of the injury at D12 to the upper thoracic cord.

\section{Case 3-Bawli's case quoted by W Wagner and $P$ Stolper in their book dated $1898^{6}$}

In 1882 a male fell about $30 \mathrm{ft}$ into a well, landing on his back. He complained of severe pain and had retention of both urine and faeces. The bladder was catheterised. There was a total loss of power and sensation in his lower limbs. This was accompanied by a protrusion of the vertebrae at the site of injury. After 1 month mobilisation took place on crutches. Three 
months after injury his condition improved when he commenced electrotherapy. When he began to walk he was unable to put weight onto the tips of his toes.

Three years after injury sores developed over his left heel with a discharging sinus. Erections were maintained but not ejaculation.

Six years after the accident his neurological condition had deteriorated. He had swollen legs, severe sinuses of his calcanea, clawing of his feet and loss of feeling over his lower limbs from L1 downwards. There was proteinuria and a sequestrum in the calcaneum. He died of oedema and amyloid disease on 14th January 1889.

- 'The post mortem examination showed amyloid degeneration of the kidneys and spleen and atrophy of both testes. There was an almost healed fracture of the 1st lumbar vertebra, whose anterior wall height was barely a quarter of the height of the posterior wall. The fracture line was oblique from posterior and above to anterior and below, so that the upper two thirds of the anterior wall appeared depressed forwards protruding into the longitudinal ligament and slightly overlaying the anterior surface of the 2nd lumbar vertebra. The posterior surface of the 1st lumbar vertebra protruded somewhat into the canal, compromising the canal space. There was considerable kinking from the compression of the cancellous bone. The 2 fracture fragments were held together by a moderately sized callous. The entire spine showed a slight prominence in the region of the upper lumbar vertebrae. At the site of the kyphosis the meninges were fused posteriorly with each other.

- The spinal cord was generally of normal shape and dimensions. In the lumbar enlargement it was somewhat widened, up to a diameter of $3 \mathrm{~cm}$ and felt soft and fluctuant at this site. The roots of the cauda equina were normal. When the lumbar enlargement was cut open a cavity filled with a serous fluid was found. This cavity was some millimetres in diameter; its position was almost exactly central, although a little to posterior and to the right. The grey and white substance could be neatly distinguished in the surround cord. The cavity extended throughout the entire lumbar enlargement over a length of $3 \mathrm{~cm}$. The columns of Goll showed ascending degeneration into the upper part of the thoracic cord.

- Nauwerk's microscopic specimens showed evidence of previous trauma. (It should be noted that the accident had been more than 6 years previously). There was evidence of a vertebral fracture, adhesive pachy- and leptomeningitis and several other clues that gave a clear hint to the genesis of the cavity formation. At the level of the fractured vertebra and ranging upwards and downwards, there were one large and several smaller cavities distributed unevenly over the transverse section but usually situated in the posterior portions and mainly to the right. These spaces were of irregular shape. One striking feature was the great increase in, and greater density of, the glial tissue. This greater density was observed around the central canal, and also generally all around the main cavity and around the smaller cavities and clefts. Obviously, this cavitation meant that the general pattern within the spinal cord was much changed. One feature that deserves special note is the finding of 2 bone fragments clearly recognisable by the jagged bone corpuscles. These fragments were situated at the edge of the cavity. There were no giant cells anywhere around these fragments'.

\section{Comment}

This man had the features of a complete spinal injury at the outset which improved to a considerable degree so much so that he could be discharged from hospital and was left with some retention of sexual function. Six years later his neurological condition had deteriorated. Post mortem showed that there were multiple cysts which extended throughout the lumbar region. They were at least $3 \mathrm{~cm}$ long.

Of great interest is the relationship between the chronic sepsis and the development of amyloidosis of his kidneys and spleen.

\section{Case 4-Wagner and Stolper's pathological case ${ }^{6}$}

In the same chapter Wagner and Stolper described the pathological findings without a case history of a case of traumatic syringomyelia. This was a case of fracture of the 5th thoracic and 1st lumbar vertebrae. Detailed investigation of the contused cord (Figure 1 - their Figure 21) revealed extensive cavitation in the centre of the cord above and below the contusion scar. The scar was roughly at the 6th thoracic segment corresponding with the fracture. They found in the cervical cord and in the upper thoracic segments, above and below the scar, a central porcelain-white discolouration which from its site in the tranverse section could not possibly be the result of secondary degeneration. The closer the sections were made to the cord scar, the larger the discoloured area was found to be, and the more anteriorly it was found to be situated. Eventually a fine cleft was found within the discoloured zone, and this cleft widened the further down they investigated. The cleft contained an aqueous and somewhat turbid grey fluid. Near the scar the cavity was bounded anteriorly only by a thick skin, which was obviously a thickening of the leptomeninges.

- 'At the back and on the sides the cavity was bounded by spinal cord substance, which inserted into the meningeal thickening with 2 rounded pincers coming from behind and from the right and left-hand sides, and having a well defined margin distinguishing it from the surrounding tissue. The meningeal thickening itself, however, 


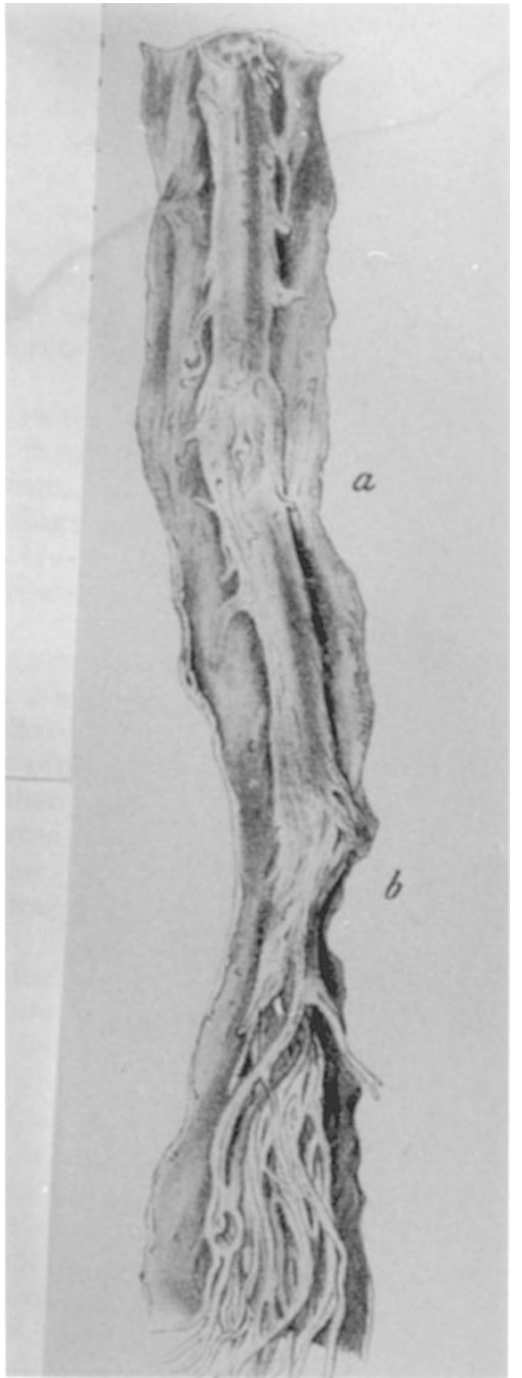

Figure 1 (Figure 21, Wagner and Stolper). ${ }^{6}$ Macroscopic appearance of the contused cord with a scar at the 6th thoracic segment. In the cervical cord and in the upper thoracic segments, above and below the scar, a central porcelain-white discolouration was found, which from its site in the transverse section could not possibly be the result of secondary degeneration

continued as a thin sheet of tissue on the lateral walls of the cavity on either side. The walls of the cavity appeared smooth, haemotoxylin stained sections showed the cavity to be fringed with a darker coloured seam of varying width. At some points the sides were found to protrude in ridges into the lumen of the cavity. Within the lumen there were occasional circular or elongated lighter tissue fragments with a dark border. These were crosssections of the delicate strands that traversed the uppermost portion of the cord cavity and were discernible with a naked eye. When the wall of the cavity was looked at at greater magnification it was seen that the stouter connective tissue fibres coming from in front were replaced posteriorly by a very delicate layer of fibres made up of neuroglia with few nuclei. This delicate fibrous layer encircled the entire posterior perimeter of the cavity. About midway along the posterior wall of the cavity there were several clusters of columnar cells, some of which were very regularly radially arranged. They had a well developed internal basement membrane and very neatly bounded small circular cavities. In the further vicinity, which appeared brighter at low magnification and which eventually merged into the region of the funiculi occupied by the longitudinal nerve fibres, there was not a single recognisable ganglion cell. All that was found was a very loose honeycomb of glial fibres with the occasional Hortega cell in the mesh-work. There were a few myelinated nerve elements and there were those peculiar structures which are not found in the normal central nervous system, but which very consistently are seen around the comminuted or softened foci. The structures concerned are fairly large cells with a very eccentric nucleus and many rigid processes. Under favourable conditions they can be traced back to their splayed insertion on the adventitia of a blood vessel. These facts as well as their Weigert neuroglia staining properties, make it absolutely certain that these are glial structures.

- The white substance, which also contained many of these glial cells, was also very abnormal. Everywhere there were swollen myelin sheaths and axons. Equally there were much dilated empty glial honeycomb spaces everywhere.

- The blood vessels everywhere had normal inner coats. However, the adventitious lymph spaces were always very wide and virtually clogged with large Hortega cells.

- Further downwards, nearer the compression site, the syrinx widened increasingly. However, this was a relative widening because the cord itself at this level had shrunk to a strand or band whose dimensions were only one half those of the cord some centimetres above and below the compressed lesion (Figure 2). The dura at this site was found to be extremely thickened, its outer portion consisted preponderantly of very dense connective tissue made up of many crossing layers of fibres. On the inside there was occasionally a layer of loose connective tissue; sometimes there were also 2 very discrete layers of this kind. Since the 2 meninges were united by individual thin strands, but also fused over larger areas, it was not always possible to distinguish the one from the other with accuracy. However, at certain sites this distinction could be made very well because of a particular configuration of the outer layers of the pia mater that occurred also higher up. On transverse section these layers appeared to be made up of very short radially arranged fibres. Anything outside this band was unquestionably dura mater. 
- The one thing that could not be done at all was to determine the inner boundary of the pia mater.

- As indicated above, the leptomeninges entering into the anterior fissure also formed the inside of the lateral walls of the cavity for a certain distance. The further down one went with the examination of the cavity the more this layer was found to occupy the posterior wall, the thicker it also tended to get, until eventually at the site of the cord compression it had completely displaced the spinal cord substance.

- Thus the transverse sections showed a thickened dura encircling a connective tissue ring made up essentially of the enormously thickened pia mater. At this level, too, the lumen was found to be traversed by vascular bands or strands. It also contained finely granular masses with a scattering of large lipid containing Hortega cells. The wall of the ring was made up as follows: The innermost layers consisted of very strong concentrically arranged connective tissue fibres with fusiform or elongated stellate cells in the interstices. Going outwards, this layer was followed by a loose layer made up of more delicate and less regularly arranged fibres with a large number of blood vessels. In this layer, which incidentally occupied only the posterior two thirds of the circumference, there were several longitudinal bundles of well preserved myelinated nerve fibres without a Schwann's sheath. Stepped section showed that these were connected with posterior funiculi, while oblique sections showed bundles containing Schwann's sheaths which were most probably posterior roots that were regenerating from the spinal ganglia. This middle layer also contained many cellular elements with a pronounced brush shape, which undoubtedly, were part of the neuroglia.

- Going further down beyond the site of spinal cord compression, the same patterns as those observed above the lesion were eventually seen. The only feature that needs mentioning here is that even at the level shortly before the disappearance of the syrinx, the cavity did not seem to be entirely surrounded by cord substance, but like the lesions described before had an anterior fibrous pia materderived wall.'

Between $\mathrm{a}$ and $\mathrm{b}$ (Figure 2 - their Figure 32) the thickened dura has been cut open with scissors. At c the thickened dura was fused to the back of the body of the 5th cervical vertebra. $d$ is in the centre of the lumen of the cavity surrounded by pial scar and neuroglial tissue which continued in Figure 3 (their Figure 31) largely surrounded by spinal cord. e and e are clefts between the dura and the cord scar. The dark areas at $\mathrm{n}$ are preserved nerve fibres, of which another 2 are seen further towards a.

\section{Comment}

There are no clinical details of this patient, only the pathological findings, but this was recognised to be a

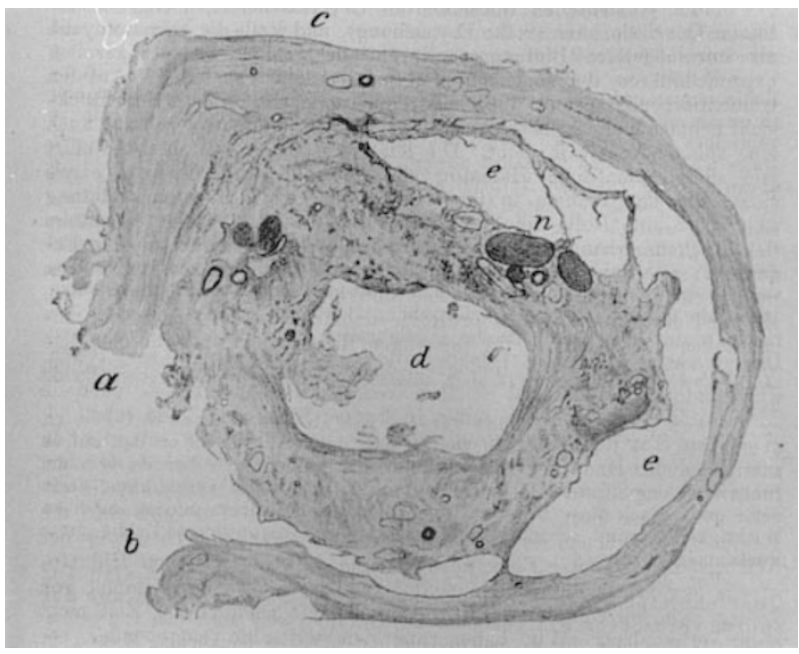

Figure 2 (Figure 32, Wagner and Stolper). ${ }^{6}$ The syrinx widened increasingly but this was only relative because the cord had shrunk to a strand or band whose dimensions were only one half those of the cord some centimetres above and below the compressed lesion. There was thickening of the dura

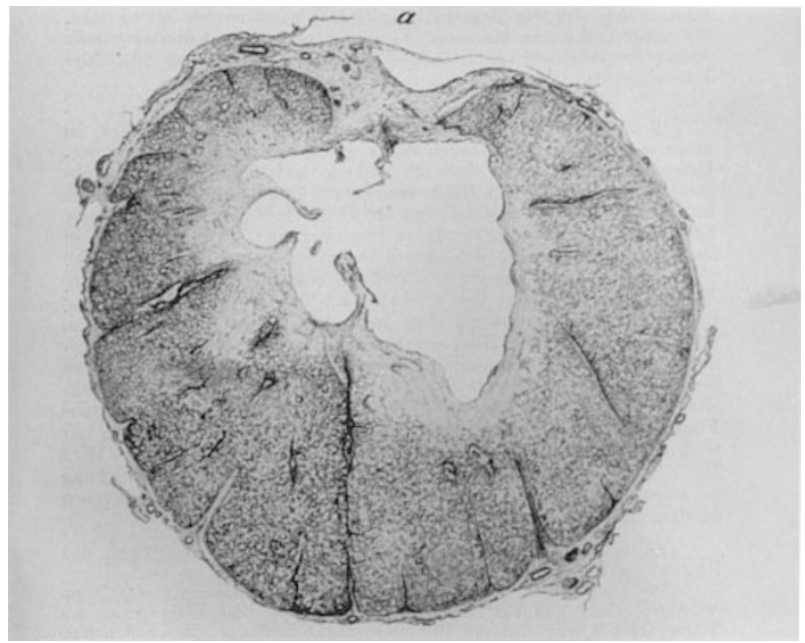

Figure 3 (Figure 31, Wagner and Stolper). ${ }^{6}$ The microscopic transverse section of the uppermost part of the cavity in the cord showed the following findings. The syrinx was approximately transverse oval in shape, wider on the right than on the left, and occupying the region of the anterior funiculi and the anterior horns as well as part of the posterior horns. The anterior boundary of this cavity was made up of fibrous tissue. At the back and on the sides the cavity was bounded by spinal cord substance

case of traumatic syringomyelia with multiple cysts and changes of ? myelomalacia extending up to the cervical region.

\section{Case 5-Victor Bellot $1917^{9}$}

A soldier aged 24 who was wounded in January 1915 by a bullet in his left buttock. Initially he was able to 
cover the $400 \mathrm{~m}$ to the rescue post but after rescue was found to have complete paralysis of his lower limbs and bladder. The bullet was thought to have entered the third lumbar vertebra. $\mathrm{He}$ recovered bladder function after 25 days. The paralysis of his lower limbs regressed. Flexion of his hips persisted and by the third month after injury he was mobilising with two sticks.

In February 1916 he was assessed for fitness to return to army service. He could walk without a stick but he had constant weakness and impairment of sensation in his lower limbs with some atrophy of the muscles. X-rays showed a bullet in the $3 \mathrm{rd}$ and 4 th lumbar vertebrae.

He was recommended for temporary discharge but first he took a holiday during which he went on many long walks, using a walking stick.

He was finally assigned to the auxiliary service but was unable to stand for long periods. Surgery was recommended but declined by the patient.
There was sudden deterioration in his condition 17 months after injury. He experienced severe pain at the level of the commencement of the lumbar vertebrae which radiated down both legs, accompanied by total paralysis and loss of sensation in his lower limbs. There was involvement of his bladder and bowels. Reflexes were absent. Lumbar puncture was clear with no signs of meningitis.

His treating doctors thought there had been a recrudescence of infection and surgery was again recommended. A laminectomy was carried out. A bullet was found in the centre of the cauda equina with purulent material around it. The patient appeared to improve post operatively and the wound healed.

He then developed an ascending myelitis and died 18 months after injury.

At post mortem macroscopic changes were found at the level of the lumbar enlargement and progressively decreasing lesions of acute myelitis which did not affect the subarachnoid space.

Table 1 Summary of cases

\begin{tabular}{|c|c|c|c|c|c|}
\hline Cases & Mitchell & Schlesinger & Bawli & Wagner and Stolper & Bellot \\
\hline Initial symptoms & $\begin{array}{l}\text { Paralysed in all four } \\
\text { limbs. Within an } \\
\text { hour power and } \\
\text { sensation returned } \\
\text { to legs and within } \\
48 \text { h to left arm }\end{array}$ & $\begin{array}{l}\text { Fractures of skull, } \\
\text { jaw and ribs. } \\
\text { Tender at D12 } \\
\text { where there was a } \\
\text { large gibbus. No } \\
\text { sensation up to one } \\
\text { third of thigh. } \\
\text { Absent knee and } \\
\text { ankle jerks and } \\
\text { priapism }\end{array}$ & $\begin{array}{l}\text { Severe pain and } \\
\text { retention of urine } \\
\text { and faeces. Total } \\
\text { loss of power and } \\
\text { sensation in lower } \\
\text { limbs. Protrusion } \\
\text { of vertebrae at } \\
\text { injury site }\end{array}$ & $\begin{array}{l}\text { Fracture of } 5 \text { th } \\
\text { thoracic and lst } \\
\text { lumbar vertebrae }\end{array}$ & $\begin{array}{l}\text { Complete paralysis } \\
\text { of lower limbs and } \\
\text { bladder. Bladder } \\
\text { paralysis } \\
\text { disappeared after } \\
25 \text { days and } \\
\text { paralysis of lower } \\
\text { limbs regressed. } \\
\text { By third month } \\
\text { mobilising with two } \\
\text { sticks }\end{array}$ \\
\hline $\begin{array}{l}\text { Onset of further } \\
\text { symptoms }\end{array}$ & $\begin{array}{l}27 \text { and } 29 \text { years after } \\
\text { injury }\end{array}$ & $\begin{array}{l}\text { Over 'subsequent } \\
\text { days' after injury. } \\
\text { Died on day } 76\end{array}$ & 6 years after injury & $?$ & $\begin{array}{l}17 \text { months after } \\
\text { injury }\end{array}$ \\
\hline Deterioration & $\begin{array}{l}\text { Pain in back and } \\
\text { shoulders. Unable } \\
\text { to distinguish } \\
\text { between hot and } \\
\text { cold. Numbness } \\
\text { below waist, } \\
\text { particularly from } \\
\text { the calves } \\
\text { downwards. } \\
\text { Difficulty } \\
\text { controlling } \\
\text { micturition } \\
\text { Followed by marked } \\
\text { symptoms of } \\
\text { progressive } \\
\text { paralysis and } \\
\text { unsteady gait } \\
2 \text { years later }\end{array}$ & $\begin{array}{l}\text { Anaesthesia } \\
\text { ascended to reach } \\
\text { the groin. Day } 3 \\
\text { pain in back and } \\
\text { abdomen. Day } 10 \\
\text { incontinent of } \\
\text { faeces. Day } 11 \\
\text { developed pressure } \\
\text { sores. Developed } \\
\text { oedema of lower } \\
\text { limbs and pressure } \\
\text { sores increased }\end{array}$ & $\begin{array}{l}\text { Neurological } \\
\text { condition } \\
\text { deteriorated. } \\
\text { Swollen legs, severe } \\
\text { sinuses, clawing of } \\
\text { feet and loss of } \\
\text { feeling in lower } \\
\text { limbs from L1 } \\
\text { downwards }\end{array}$ & $?$ & $\begin{array}{l}\text { Severe pain at the } \\
\text { level of the start of } \\
\text { the lumbar } \\
\text { vertebrae which } \\
\text { radiated down both } \\
\text { legs accompanied } \\
\text { by total paralysis } \\
\text { and loss of } \\
\text { sensation in lower } \\
\text { limbs. Involvement } \\
\text { of bladder and } \\
\text { bowels. Absent } \\
\text { reflexes. Following } \\
\text { laminectomy he } \\
\text { developed ascend- } \\
\text { ing myelitis and } \\
\text { died }\end{array}$ \\
\hline Post mortem & No & Yes & Yes & Yes & Yes \\
\hline Cyst & Unknown & $\begin{array}{l}\text { Several cysts } \\
\text { extending from } \\
\text { level of injury to } \\
\text { upper thoracic cord }\end{array}$ & $\begin{array}{l}\text { Multiple cysts } \\
\text { extended through } \\
\text { the lumbar region, } \\
\text { at least } 3 \mathrm{~cm} \text { long }\end{array}$ & $\begin{array}{l}\text { Extensive cavitation } \\
\text { centre of cord } \\
\text { above and below } \\
\text { the contusion scar }\end{array}$ & Ascending myelitis \\
\hline
\end{tabular}




\section{Comment}

This man had features of post traumatic syringomyelia: an initial wound causing a complete paraplegia, regression of the neurological condition, and then, precipitated by the trauma of long walks, pain radiating down both lower limbs and ascent of the lesion causing a sudden deterioration in function. At post mortem ascending myelitis was found. No histological details are given as to what this phrase 'myelitis' meant. It is not clear whether the cyst he developed was of infective origin but, in view of the normal initial lumbar puncture, this probably was a post traumatic cyst.

\section{Discussion}

In carrying out their extensive search Barnett and Jousse $^{1}$ only found the case of Bawli ${ }^{3}$ which they recognised as being post traumatic syringomyelia, but there are these further four cases which fulfil the criteria of post traumatic syringomyelia (Table 1).

One patient had sustained a cervical injury and the remaining four had thoraco-lumbar injuries which is the common site for cysts to arise. At that time, cervical patients died almost immediately after injury so too much significance cannot be attached to this distribution.

Post mortems were carried out on four of the five patients. Two patients were found to have multiple cysts and the actual cyst extended for several segments both caudally and rostrally. Histological findings by pathologists were available in three of the five cases which confirm the diagnosis of syringomyelia, one being included in Schlesinger's textbook on the subject. ${ }^{8}$ Bellot's case presents problems. The clinical features are unquestionably those of ascending syringomyelia. The patient had a post mortem but this was carried out in the height of the war and histological findings were not available. The term 'myelitis' was used which has been condemned as being non-descriptive so its meaning is unclear.

The clinical features fulfil the criteria: four of the five patients showed spinal injury with recovery and then deterioration, varying from a few weeks to 29 years after injury. This timing corresponds with current experience. One patient who died at 76 days did not show recovery. Three patients had the typical features of sudden onset of pain at the appropriate level and in Bellot's case this was precipitated by the trauma of walking. There was ascent of the lesion in all four patients where clinical findings were available.

Barnett and Jousse accepted Bawli's case as being post traumatic syringomyelia. A second case described by Wagner and Stolper, and Schlesinger's case both fulfil the pathological criteria. The clinical features of Mitchell's and Bellot's cases would support this diagnosis even in the absence of post mortem corroboration.

Wagner and Stolper reviewed the literature. They believed that trauma played a role in the development of syringomyelia but there was considerable argument at the time. Some authors, following the lead of the pathologists, considered syringomyelia to be an outpouching of the central canal. Others thought the cavity occurred as a result of the disintegration of lengthy gliomas. A third school of thought was that the cavitation occurred as a result of chronic congestion or that it was a congenital developmental abnormality. Wagner and Stolper accepted that not all cases were due to the same cause.

Wagner and Stolper ${ }^{6}$ cited Bawli's case as they were convinced that it proved the relationship between syringomyelia and trauma, both clinically and anatomically. They stressed the differential diagnoses of idiopathic syringomyelia and syringomyelia following trauma and listed the following clues which pointed to a history of trauma as the causative factor:

'1. Evidence of a healed vertebral fracture or spinal dislocation. While the patient is alive this will take the form of kyphosis, whereas non-traumatic syringomyelia tends to be associated with scoliosis.

2. Traumatic syringomyelia is more frequently encountered in parts of the spine where fractures tend to occur, that is to say, the lower thoracic and the lumbar spine. The site of preference of nontraumatic syringomyelia is the cervical cord.

3. Thickening and adhesions of the meninges with each other and with the wall of the vertebral canal. This would suggest an exogenous cause unlike endogenous non-traumatic syringomyelia that arises from a disintegrating glioma or central gliosis. This is why in the traumatic variety we see proliferation of the pia mater, which is not observed in the non-traumatic variety (Bawli).

4. When looked at on a transverse section traumatic cavities tend to be in the posterior funiculus, or if they are not there they will be exclusively in the anterior horns. The site of preference of the nontraumatic variety is the area of the posterior commissure.

5. Haemoglobin without any underlying idiopathic vascular disease is sometimes found in traumatic syringomyelia, whereas this finding is the rule in non-traumatic syringomyelia'.

They amplified their views by reporting on a further case (my case 4) and concluded:

- 'In the light of all these investigations we are convinced that traumatic intramedullary cavitation is the direct result of trauma. The forcible kinking of the spine will stretch the cord, and this together with slight compression at the moment of violence will lead to the formation of delicate clefts and fissures. Individual bundles of nerve fibres will be loosened and disrupted in that context. It is not inconceivable that this may happen without any extravasation of blood. In those cases the clinical picture following the lesion may be so slight as to 
be virtually missed. Not infrequently, however, there may be major haemorrhaging into these cavities and this will very rapidly produce a clinical picture of haematomyelia. Either way, this may be presumed to stimulate the proliferation of the glia'.

\section{Conclusion}

These views, expressed more than 100 years ago, are extra-ordinarily prescient. It shows that credit should be given to Wagner and Stolper for the first delineation of the condition and, even in the absence of experimental work, their views on the pathogenesis have stood the test of time.

\section{Acknowledgements}

I am grateful to Professor Alan Rossier for drawing my attention to the case of Schlessinger and to Marie-France Weiner and Karin Band for translating the French and German texts.

\section{References}

1 Barnett HJM, Jousse AT. Syringomyelia as a Late Sequel to Traumatic Paraplegia and Quadriplegia - Clinical Features. In: Barnett HJM, Foster JB, Hudgson P (eds). Syringomyelia. Saunders \& Co: London, 1973, pp 129-153.

2 Strümpell A. Beiträge zur Pathologie des Rückenmarks. Archive für Psychiatrie und Nervenkrankheiten 1880; 10: 676.

3 Bawli J. Syringomyélie et Traumatisme Médullaire. Thése inaugurale 1896, Koningsberg.

4 Weisenberg TH. Sensory and motor disturbances in parts above the distribution involved by definite organic lesions of the spinal cord. J Nerv Ment Dis 1907; 34: 434.

5 Strong OS. A case of sacral cord injury and a subsequent unilateral syringomyelia. Neurol Bull (Columbia University, New York) 1919; 2: 277.

6 Wagner W, Stolper P. Die Verletzungen der Wirbelsäule und des Rückenmarks. Verlag von Ferdinand Enke: Stuttgart, 1898, pp $111-125$.

7 Mitchell JK. Incomplete sections of nerves; injuries of the spinal cord and its neighborhood. In: Remote Consequences of Injuries of Nerves and Their Treatment. Lea Brothers \& Co: Philadelphia, 1895 , pp $114-117$.

8 Schlesinger H. Die Syringomyelie: Eine Monographie. Franz Deuticke: Leipzig und Wien, 1895, pp 238-240.

9 Bellot V. Balle de fusil dans la queue de cheval. Bulletin de 1-Academie de Medecine 1917; 24: 749-753. 